\title{
Expression of elongation factor-2 kinase contributes to anoikis resistance and invasion of human glioma cells
}

\author{
Li ZHANG ${ }^{1, \#}$, Yi ZHANG ${ }^{1, \#}$, Xiao-yuan LIU ${ }^{1}$, Zheng-hong QIN¹, Jin-ming YANG ${ }^{2, *}$
}

${ }^{1}$ Department of Pharmacology, College of Pharmaceutical Science, Soochow University, Suzhou 215123, China; ${ }^{2}$ Department of Pharmacology and Penn State Hershey Cancer Institute, the Pennsylvania State University College of Medicine, Hershey, PA, USA

Aim: To determine whether elongation factor-2 kinase (eEF-2 kinase) contributes to the malignant phenotype of glioblastoma multiforme by promoting the migration and invasion of glioma cells. The mechanism involved was also explored.

Methods: Human glioma cell lines T98G and LN-229 were used. The expression of eEF-2 kinase was silenced using siRNA, and the invasive potential of tumor cells was assessed using a wound-healing assay and a Matrigel invasion assay. Apoptosis was determined using propidium iodide (PI) staining and Western blot analysis of cleaved caspase-3.

Results: Silencing the expression of eEF-2 kinase by siRNA significantly suppressed both the migration and invasion of human glioma cells. Silencing eEF-2 kinase expression also sensitized glioma cells to anoikis, thereby decreasing tumor cell viability in the absence of attachment. Treatment of tumor cells with the caspase inhibitor z-VAD-fmk down-regulated Bim accumulation and abolished glioma cell sensitivity to anoikis.

Conclusion: The results suggest that the expression of eEF-2 kinase contributes to migration and invasion of human glioma cells by protecting them from anoikis. eEF-2 kinase expression may serve as a prognostic marker and a novel target for cancer therapy.

Keywords: eEF-2 kinase; migration; invasion; anoikis; glioma

Acta Pharmacologica Sinica (2011) 32: 361-367; doi: 10.1038/aps.2010.213; published online 31 Jan 2011

\section{Introduction}

Elongation factor-2 kinase (eEF-2 kinase, also known as calmodulin-dependent protein kinase III) is a unique calmodulin/ calcium-dependent enzyme that inhibits protein synthesis. Expression of eEF-2 kinase has been reported to be up-regulated in several types of malignancies, including gliomas ${ }^{[1,2]}$. eEF-2 kinase phosphorylates eEF-2, a 100-kDa protein that promotes ribosomal translocation from the A to the $\mathrm{P}$ site in eukaryotic tissues, which induces movement of mRNA along the ribosome during translation ${ }^{[3]}$. Phosphorylation of eEF-2 at Thr56 by eEF-2 kinase decreases the affinity of eEF-2 for ribosomes and terminates peptide elongation, thereby inhibiting protein synthesis.

The role of protein synthesis in the growth and survival of cancer cells has gained widespread attention. For example, mitotic cells show a $20 \%-40 \%$ decrease in protein synthesis

\footnotetext{
\# These two authors contributed equally to this study.

* To whom correspondence should be addressed.

E-mail juy16@psu.edu

Received 2010-10-04 Accepted 2010-11-29
}

compared to cells in inter-phase. In addition, a transient decrease in protein synthesis is characteristically observed at the $G_{1} / S$ interface ${ }^{[4,5]}$. Altered protein synthesis can transform cells by interfering with the expression and activity of translation factors such as eIF2 alpha and its specific protein kinase, $\mathrm{PKR}^{[6]}$. There is also abundant evidence suggesting that the downstream effects of growth factors require transient inhibition of protein synthesis ${ }^{[7]}$. In fact, a variety of processes important to cell proliferation, such as polyamine transport ${ }^{[8]}$; ATP turnover ${ }^{[9]}$; expression of early growth response genes, such as $c$-fos and $c$-jun ${ }^{[10]}$; and activation of the ribosomal protein, S6 kinase ${ }^{[11]}$, as well as specific signaling molecules, such as MAP kinase ${ }^{[12]}$ and JNK/SAPK kinase ${ }^{[13]}$, are stimulated by inhibitors of protein synthesis ${ }^{[14]}$. In addition, exposure of 3T3 cells to cycloheximide or puromycin results in the induction of DNA synthesis and cell division ${ }^{[15]}$. Connolly et $a l^{[16]}$ demonstrated that the protein expression level of eEF-2 kinase in non-transformed cells is kept low by proteasomal degradation. In contrast, as cells transform from immortalized to highly malignant, the expression level of eEF-2 kinase increases. These results are consistent with our 
original reports demonstrating that eEF-2 kinase is regulated by ubiquitin-mediated proteasomal degradation ${ }^{[17]}$, and that eEF-2 kinase is constitutively up-regulated in cancer cell lines and tumor specimens ${ }^{[18,19]}$. Connolly et al also reported that hypoxic breast epithelial cells down-regulate protein synthesis by disrupting the proteasome-mediated degradation of eEF-2 kinase and activation of $4 \mathrm{EBP}-\mathrm{1}^{[16]}$. In contrast, breast cancer cells have constitutively activated eEF-2 kinase. These studies suggest that eEF-2 kinase might have a role in promoting cancer cell survival by favoring their growth and dissemination. Anchorage-independent growth and the capacity to invade are characteristics of glioma cells. Migration and invasion of glioma cells is a complex process that involves multiple biological features such as tumor cell adhesion and motility, secretion of proteases by tumor cells, and the ability to survive in the absence of anchorage ${ }^{[20,21]}$. We report here that the expression of eEF-2 kinase in glioma cells confers resistance to anoikis, a form of apoptosis triggered by the loss of cell-to-cell or cell-to-matrix anchorage, and favors migration and invasion of human glioma cells. Our results provide new evidence that eEF-2 kinase might be an effective target in brain cancer therapy.

\section{Materials and methods Cell lines and culture}

The human glioblastoma cell lines T98G and LN-229 were obtained from the Shanghai Institutes for Biological Sciences. The glioma cells were cultured in DMEM supplemented with $10 \%$ fetal bovine serum, 100 units $/ \mathrm{mL}$ penicillin, and 100 $\mu \mathrm{g} / \mathrm{mL}$ streptomycin. Cells were maintained at $37^{\circ} \mathrm{C}$ in a humidified atmosphere containing $5 \% \mathrm{CO}_{2}$ and $95 \%$ air.

\section{Antibodies and reagents}

The antibodies used in this study were as follows: monoclonal anti-eEF-2 kinase antibody (NOVUS), polyclonal cleaved caspase-3 antibody and polyclonal caspase-3 antibody recognizing the full-length pro-enzyme (Sigma), polyclonal antiBim antibody (H-191; Santa Cruz), monoclonal anti- $\beta$-actin antibody (Santa Cruz), caspase inhibitor z-VAD-fmk (Sigma), eEF-2 kinase-siRNA (Shanghai Gene-Pharma Co, China), and poly-HEMA (Sigma).

\section{siRNA preparation and transfection}

The siRNA sequence used to target eEF-2 kinase mRNA corresponded to amino acids 144 to 164 (5'-AAGCTCGAACCAGAATGTC-3') of the coding region relative to the start codon. The siRNA duplex with the following sense and antisense sequences was used, 5'-AAGCUCGAACCAGAAUGUCTT-3' (sense) and 5'-GACAUUCUGGUUCGAGCUUTT-3' (antisense) (prepared by Shanghai Genepharma Research, Inc). For transfection, cells in the exponential phase of growth were plated in $60-\mathrm{mm}$ tissue culture dishes at $5 \times 10^{5}$ cells per dish, grown for $24 \mathrm{~h}$, and then transfected with siRNA using oligofectamine and Opti-MEMI-Reduced Serum medium following the manufacturer's protocol.

\section{Wound-healing assay}

Cells $\left(5 \times 10^{5}\right.$ cells in $2 \mathrm{~mL}$ per well) were transfected with an eEF-2 kinase-targeted siRNA or a non-targeting scrambled siRNA and then plated onto standard 6-well tissue culture plates cultured in medium containing $10 \%$ FBS to nearly confluent cell monolayers. Cell monolayers were then carefully wounded using a $200-\mu \mathrm{L}$ sterile pipette tip, and any cellular debris was removed by washing with PBS. The wounded monolayers were then incubated in medium containing 10\% FBS for $24 \mathrm{~h}$ and photographed using a phase-contrast microscope (Eclipse TE 200, Nikon Inc, Melville, NY, USA). The experiments were performed in triplicate wells and repeated at least three times.

\section{Invasion assay}

Invasion assays were carried out in modified Boyden chambers with filter inserts with 8 - $\mu \mathrm{m}$ pores in 24 -well plates (Corning, NY, USA). The surfaces of the filters were coated with 50 $\mathrm{mg} / \mathrm{L}$ ice-cold Matrigel (Matrigel basement membrane matrix, BD Bioscience, NJ, USA). The lower chamber was filled with medium containing $10 \%$ serum. Cells were transfected with an eEF-2 kinase-targeted siRNA or a non-targeting scrambled siRNA. Sixty hours later, the cells were seeded into the upper chamber of a 24-well chemotaxis chamber transwell. Cells $\left(1 \times 10^{5}\right.$ cells/well $)$ were washed with PBS twice, re-suspended in $200 \mu \mathrm{L}$ of serum-free medium, and then transferred into the upper chamber. After a 24-h incubation, the filters were gently removed from the chambers, and the cells on the upper surface were removed by wiping with a cotton swab. Cells that had invaded to the lower surface areas were fixed with icecold methanol, stained with crystal violet, and counted in 10 randomly selected fields under a microscope (100×). Results shown are representative of three independent experiments.

\section{Anoikis assay}

Cells $\left(5 \times 10^{5}\right.$ cells in $2 \mathrm{~mL}$ per well) were transfected with an eEF-2 kinase siRNA or a non-targeting scrambled siRNA. Sixty hours later, cells were plated onto standard 6-well tissue culture plates or poly-HEMA-coated plates to prevent attachment. Following a $24-\mathrm{h}$ incubation at $37^{\circ} \mathrm{C}$ in a humidified atmosphere containing $5 \% \mathrm{CO}_{2}$ and $95 \%$ air, viability of the cells was determined using the trypan blue exclusion method. Apoptosis was determined by propidium iodide (PI) staining and Western blot analysis of cleaved caspase-3. To stain apoptotic nuclei with PI, cells were stained with a PI dye solution at $4{ }^{\circ} \mathrm{C}$ in the dark for $30 \mathrm{~min}$, and then the samples were analyzed on a FC500 Beckman-Counter flow cytometer. Active caspase-3, which is present in cells undergoing apoptosis, was detected by Western blot analysis using a polyclonal anti-caspase-3 antibody that recognizes the cleaved active caspase-3.

\section{Western blot analysis}

Cell lysates were prepared in TNT buffer $(20 \mathrm{mmol} / \mathrm{L}$ Tris$\mathrm{HCl}, \mathrm{pH}$ 7.4, $200 \mathrm{mmol} / \mathrm{L} \mathrm{NaCl}, 1 \%$ Triton X-100, 1 mmol/L phenylmethylsulfonyl fluoride, and $1 \%$ aprotinin), and proteins were resolved by SDS-PAGE. The blots were incubated 
in blocking solution consisting of $5 \%$ skim milk in $10 \mathrm{mmol} / \mathrm{L}$ Tris- $\mathrm{HCl}, \mathrm{pH} 8.0,150 \mathrm{mmol} / \mathrm{L} \mathrm{NaCl}$, and $0.1 \%$ Tween 20 at room temperature for $1 \mathrm{~h}$ and then immuno-blotted with the indicated antibodies. Proteins were detected using the enzyme-linked chemiluminescence (ECL) method. $\beta$-Actin was used as a loading control.

\section{Statistical analysis}

Data were shown as mean $\pm S D$. Differences between individual groups were analyzed using student's $t$-test. All $P$ values were 2 -sided; $P<0.05$ was considered significant. Analyses were performed using the GraphPad Prism 4.0 package (GraphPad, San Diego, CA, USA).

\section{Results}

\section{Effect of eEF-2 kinase on glioma cell migration and invasion}

To determine the role of eEF-2 kinase in the malignant phenotype of glioma, we utilized an siRNA approach to inactivate this enzyme. Human glioma cell lines, T98G and LN229, transfected with eEF-2 kinase-targeted siRNA showed an $85 \%-90 \%$ reduction in eEF-2 kinase protein expression $60 \mathrm{~h}$ after transfection when compared with the cells transfected with a non-targeting siRNA (Figure 1).

We next compared the invasive potentials and migrating capabilities of T98G and LN229 cells with or without silencing of eEF-2 kinase expression. Invasion was assessed using a Matrigel chamber assay, and the ability to migrate was examined using a wound-healing assay. As shown in Figure 2A, wound healing after $24 \mathrm{~h}$ was significantly inhibited in T98G and LN229 cells when eEF-2 kinase was knocked down in cells compared with control cells that were transfected with a nontargeting siRNA. Consistent with the wound-healing assay, the invasiveness of the glioma cells in which eEF-2 kinase expression was silenced also decreased considerably compared with control cells (Figure 2B). These results suggest that the expression of eEF-2 kinase plays an important role in the invasion and migration of glioma cells.

\section{Effect of eEF-2 kinase on cell viability in the absence of matrix attachment}

To determine whether eEF-2 kinase affects the survival of glioma cells in the absence of matrix attachment, we determined the viability of T98G and LN229 cells grown either as monolayers attached to plastic or in suspension on polyHEMA. Figures 3C and 3D show that the viability of glioma cells cultured in suspension was significantly reduced in eEF-2 kinase knock-down cells when compared with control cells. In contrast, reduction of eEF-2 kinase expression had no effect on the viability of cells grown attached to a matrix (Figure 3A and $3 \mathrm{~B})$. These results suggest that expression of eEF-2 kinase has a role in the survival of human glioma cells in the absence of anchorage.

\section{Expression of eEF-2 kinase confers resistance to anoikis}

To determine whether the pro-survival function of eEF-2 kinase, as evidenced in Figure 3, was mediated through the
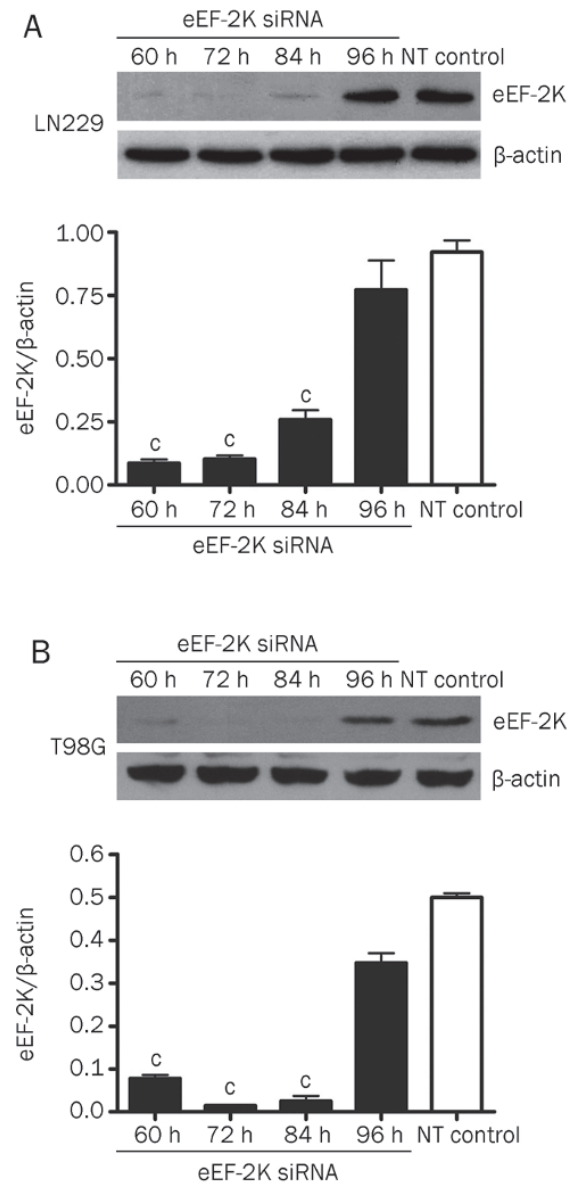

Figure 1. eEF-2 kinase expression was silenced by siRNA. Human glioma cell lines LN229 and T98G were transfected with an eEF-2 kinasetargeted siRNA. Expression of eEF-2 kinase was analyzed by Western blot analysis. Each bar represents mean $\pm \mathrm{SE}$ of three separate experiments. $P$-values were determined by $t$-test. ${ }^{c} P<0.01$ vs NT control.

inhibition of anoikis, we compared the apoptotic properties of T98G and LN229 cells with or without silencing of eEF-2 kinase expression. As shown in Figure 4, silencing of eEF-2 kinase expression by siRNA resulted in the activation of caspase-3 in T98G and LN229 cells cultured in suspension on poly-HEMA but had a barely detectable effect on cells grown as monolayers attached to plastic (Figure 4A and 4B). The PI apoptotic assay also demonstrated that when cultured in suspension on poly-HEMA, there was an increase in the subdiploid peak of apoptotic nuclei in the DNA histogram in the glioma cells with silencing of eEF-2 kinase expression when compared with that of the cells transfected with a non-targeting siRNA (Figure 4B), indicating an induction of apoptosis. The caspase inhibitor z-VAD-fmk abolished the sub-diploid DNA peak observed in the cells transfected with an eEF-2 kinase-targeted siRNA (Figure 4B). These results suggest a role for eEF-2 kinase in the inhibition of anoikis in tumor cells.

\section{Down-regulation of Bim correlates with the anoikis resistance} conferred by eEF-2 kinase

We next explored the possible mechanism involved in anoi- 
A

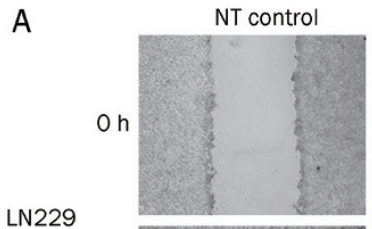

LN229
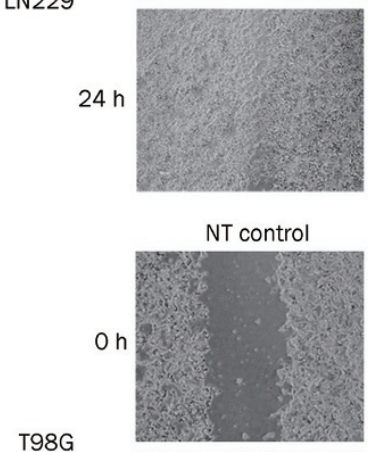

T98G

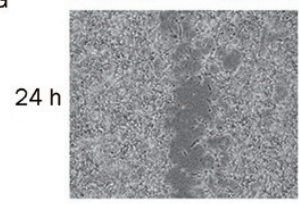

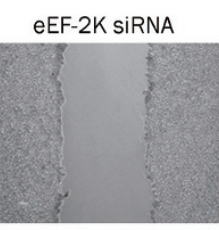

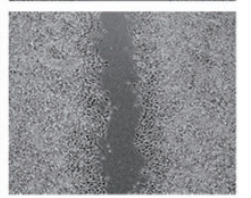

eEF-2K SIRNA
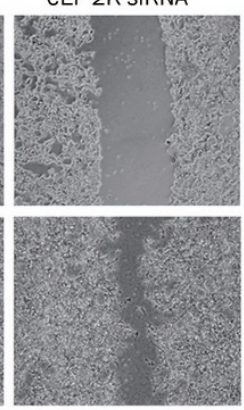
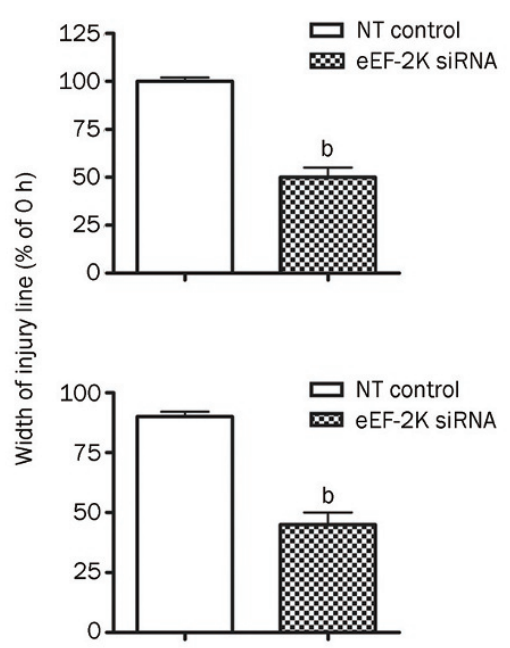

B
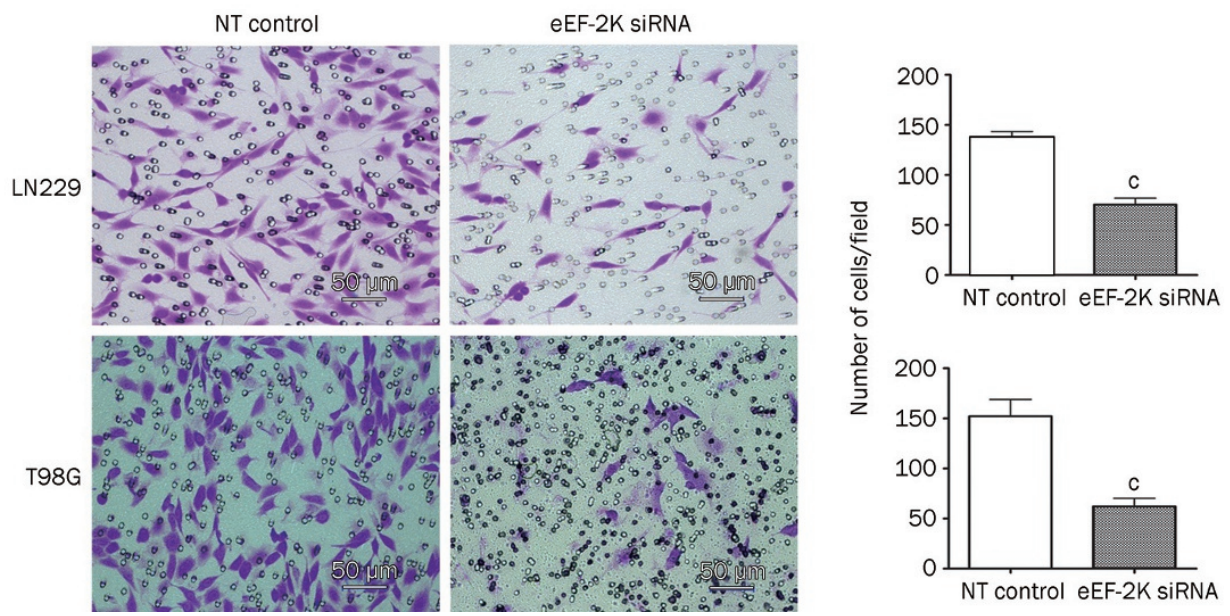

Figure 2. Effect of eEF-2 kinase expression on migration and invasion of glioma cells. LN229 and T98G cells were transfected with an eEF-2 kinase-targeted siRNA or a scrambled siRNA, and their ability to migrate and invade was determined as described in Materials and methods. (A) Migration; (B) Invasion. P-values were determined by $t$-test. ${ }^{\mathrm{b}} P<0.05$, ${ }^{\mathrm{c}} P<0.01$ compared with NT control.

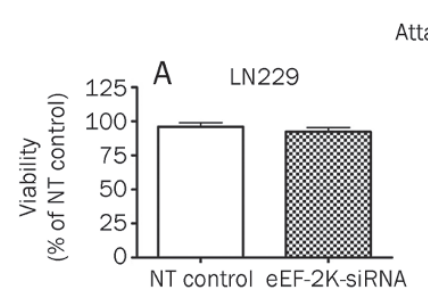

Attached
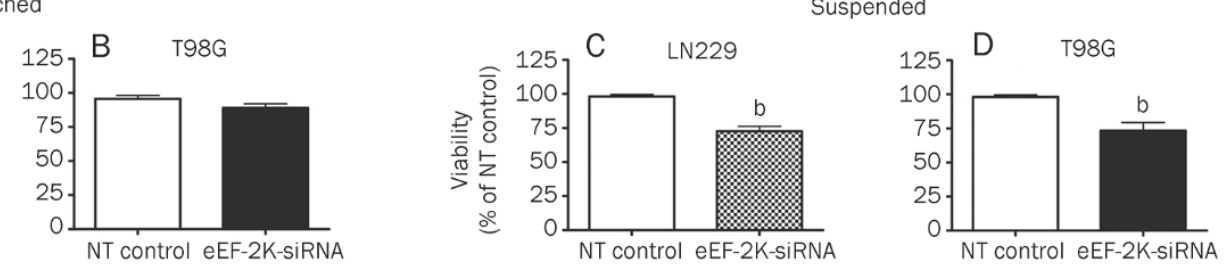

Figure 3. Effect of eEF-2 kinase expression on cell viability in the absence of attachment. LN229 and T98G cells transfected with an eEF-2 kinase SiRNA or a scrambled siRNA were seeded on plastic (attached) or on poly-HEMA (suspended) for $24 \mathrm{~h}$, and then cell viability was determined by trypan blue assay. Each bar represents mean \pm SEM of three experiments. $P$-values were determined by $t$-test. ${ }^{\mathrm{b}} P<0.05$ compared with scrambled cells.

kis resistance associated with eEF-2 kinase expression. We determined whether resistance to anoikis in glioma cells was associated with a down-regulation of Bim, a pro-apoptotic $\mathrm{BH} 3-$ only protein that plays a crucial role in regulating anoikis $^{[22]}$. As demonstrated in Figure 5, silencing of eEF-2 kinase expression caused an increase of Bim in glioma cells, and this increase in the Bim protein level was more remarkable when the eEF-2 kinase siRNA-treated cells were grown in suspension on poly-HEMA (Figure 5). These observations suggest that the enhanced sensitivity to anoikis caused by the silencing 
A

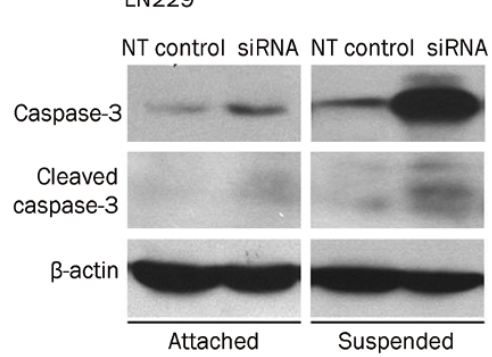

B

T98G

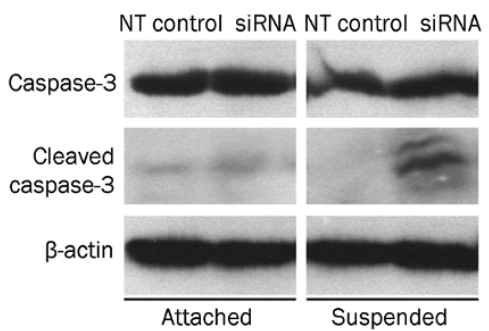

C
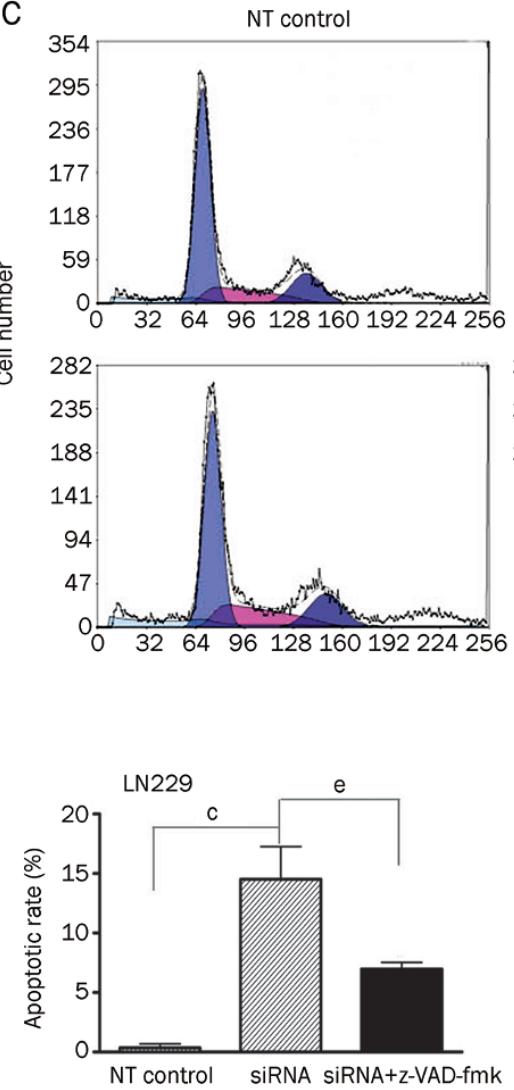
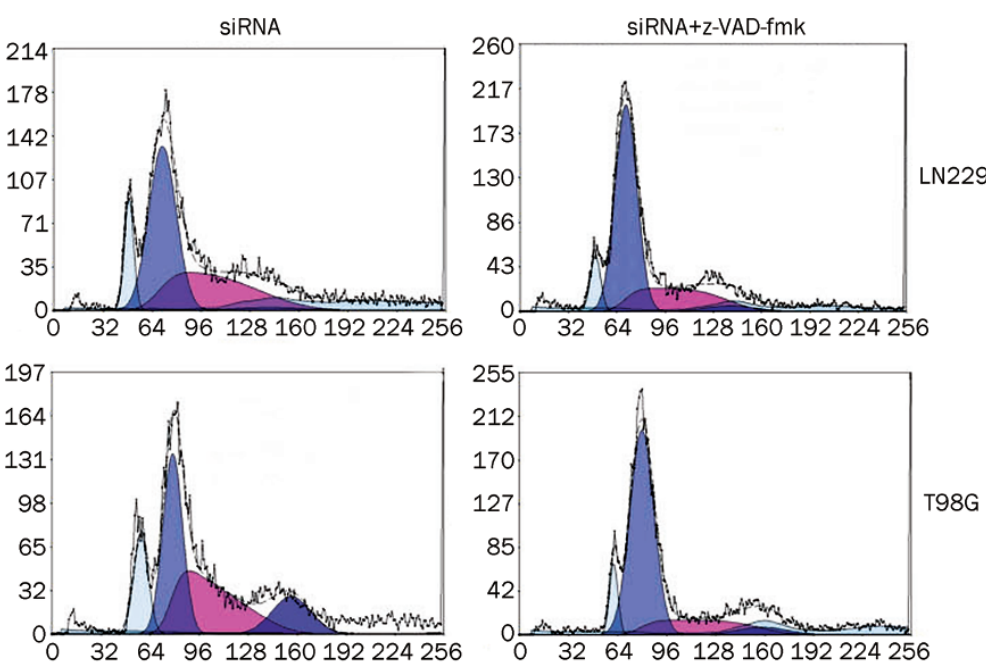

DNA content

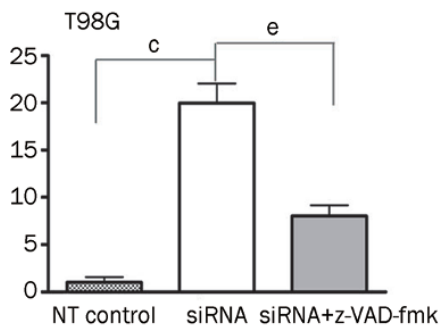

Figure 4. Effect of eEF-2 kinase expression on glioma cell sensitivity to anoikis. (A and B) LN229 and T98G cells transfected with an eEF-2 kinase SiRNA or scrambled siRNA were seeded on plastic (attached) or on poly-HEMA (suspended) for $24 \mathrm{~h}$. The levels of caspase-3 and cleaved caspase-3 were examined by Western blot analysis. B-Actin was used as a loading control. (C) LN229 and T98G cells transfected with an eEF-2 kinase siRNA or a scrambled siRNA were seeded on plastic (attachment), poly-HEMA (suspension), followed by treatment with caspase inhibitor, z-VAD-fmk, for $24 \mathrm{~h}$. Apoptosis was determined by flow cytometric analysis of PI-stained apoptotic nuclei. Each bar represents mean \pm SEM of three separate experiments. $P$-values were determined by $t$-test. ${ }^{c} P<0.01$ vs NT control group. ${ }^{e} P<0.05$ vs siRNA group.

of eEF-2 kinase expression might be due to the up-regulation of Bim protein expression.

\section{Discussion}

Previous studies showed that activation of eEF-2 kinase promotes autophagy and survival in cancer cells ${ }^{[23]}$. In the current study, we sought to determine a role for eEF-2 kinase in the malignant phenotype of glioblastoma multiforme, one of the most common childhood malignancies and a cancer of increasing significance in adults. The results of our study suggest a role for eEF-2 kinase in the progression of glioma, as expression of this kinase appears to promote migration and invasion of glioma cells (Figure 2), protect viability when tumor cells lose anchorage (Figure 3), and render cells resistant to anoikis (Figure 4), a form of apoptosis induced by loss of matrix or cellular attachment, which is often defective in tumor cells. Moreover, we demonstrate that down-regulation of Bim is involved in the resistance to anoikis in tumor cells expressing high levels of eEF-2 kinase (Figure 5).

Migration and invasion involves the spread of glioma cells 


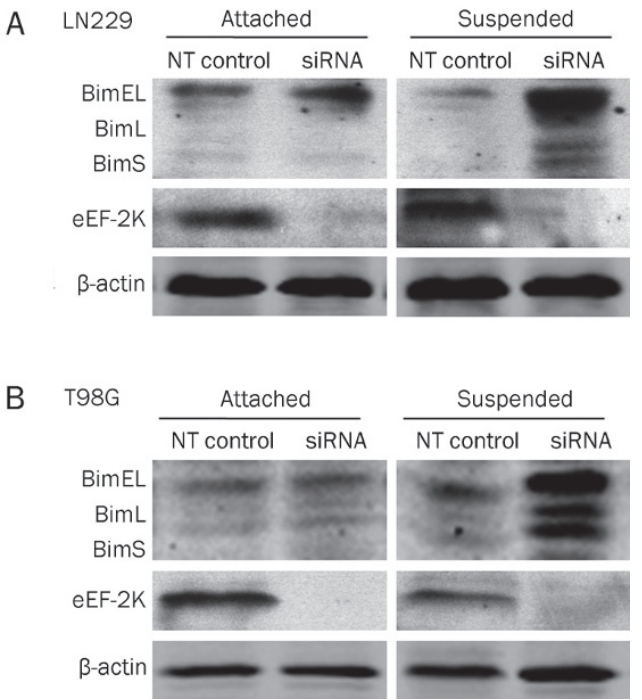

Figure 5. Effect of silencing of eEF-2 kinase expression on Bim protein expression level in glioma cells cultured in suspension or as an attached monolayer. (A) LN229 and (B) T98G cells transfected with an eEF-2 kinasetargeted siRNA or a scrambled siRNA were seeded on plastic (attached) or on poly-HEMA (suspended) for $24 \mathrm{~h}$. Cell lysates were prepared from monolayer or suspension cultures, and Bim (BimEL, BimL, and BimS) and eEF-2 kinase proteins were detected by Western blot analysis. $\beta$-Actin was used as a loading control.

from a primary tumor site to the surrounding normal tissues. These processes involve the coordination of several signaltransduction pathways that allow cancer cells to proliferate, remodel their surrounding environment, invade to distant sites and re-establish the tumor ${ }^{[24]}$. Recently, studies have shown that initiation of several pro-survival genes that maintain growth can enhance cell migration ${ }^{[25]}$. In this study, we found that eEF-2 kinase plays an important role in tumor migration and invasion, which is consistent with the role of this kinase in cell survival, as reported by us and others ${ }^{[23,26]}$.

Resistance to apoptosis (anoikis) is a hallmark of migrating and invasive glioma cells. Here, we show that expression of eEF-2 kinase in human glioma cells can suppress anoikis (Figures 3 and 4). In the absence of anchorage, human glioma cells have high viability (Figure 3 ) and low rates of apoptosis (Figure 4). Silencing of eEF-2 kinase expression in glioma cells produces lower viability and higher rates of apoptosis (Figures 3 and 4). These observations indicate that in the absence of attachment, promotion of glioma cell survival by eEF-2 kinase may be the result of inhibition of anoikis. Bim, a BH3-only pro-apoptotic protein belonging to the Bcl-2 family, plays a critical role in triggering anoikis. For example, inhibition of Bim induction has been found to be the mechanism responsible for the anoikis deficiency caused by $\mathrm{G}_{1} / \mathrm{S}$ cell cycle arrest ${ }^{[27]}$. In addition, Bim has been shown to be a tumor suppressor and a key determinant of paclitaxel sensitivity in epithelial tumors ${ }^{[28]}$. We found a converse relationship between eEF-2 kinase expression and Bim accumulation (Figure 5); Bim is reduced in cells with high expression of eEF-2 kinase, and silencing of eEF-2 kinase expression results in the up-regulation of Bim expression levels (Figure 5).

In summary, the current study identified eEF-2 kinase as a regulator of glioma cell migration and invasion and as a suppressor of anoikis. Because the ability of glioma cells to invade and migrate and to develop resistance to treatment represents two critically important malignant characteristics, and defective anoikis likely contributes to both of these features, re-establishing sensitivity to anoikis may represent a novel therapeutic strategy for malignant glioma. Thus, the results reported here provide support for further studying eEF-2 kinase as a target for cancer therapy.

\section{Acknowledgements}

This project was supported by the National Natural Sciences Foundation of China (K113416510) and Natural Science Foundation of Jiangsu Province of China (BK2010224) and US Public Health Service R01CA135038.

\section{Author contribution}

Jin-ming YANG designed research; Li ZHANG, Yi ZHANG, Xiao-yuan LIU performed research; Li ZHANG and Yi ZHANG analyzed data; Zheng-hong QIN contributed new analytical and tools; Li ZHANG and Yi ZHANG wrote the paper.

\section{References}

1 Serfass L, Van Herpen C, Saghatchian M. Molecular targets and cancer therapeutics. Eur J Cancer 2007; 43: 1494-5.

$2 \mathrm{Wu} \mathrm{H}$, Yang JM, Jin S, Zhang H, Hait WN. Elongation factor-2 kinase regulates autophagy in human glioblastoma cells. Cancer Res 2006; 66: 3015-23.

3 Ryazanov AG, Rudkin BB, Spirin AS. Regulation of protein synthesis at the elongation stage. New insights into the control of gene expression in eukaryotes. FEBS Lett 1991; 285: 170-5.

4 Hait WN, Wu H, Jin S, Yang JM. Elongation factor-2 kinase: its role in protein synthesis and autophagy. Autophagy 2006; 2: 294-6.

5 Celis JE, Madsen P, Ryazanov AG. Increased phosphorylation of elongation factor 2 during mitosis in transformed human amnion cells correlates with a decreased rate of protein synthesis. Proc Natl Acad Sci USA 1990; 87: 4231-5.

6 Donze O, Jagus R, Koromilas AE, Hershey JW, Sonenberg N. Abrogation of translation initiation factor elF-2 phosphorylation causes malignant transformation of NIH 3T3 cells. Embo J 1995; 14: 382834.

7 Herschman HR. Primary response genes induced by growth factors and tumor promoters. Annu Rev Biochem 1991; 60: 281-319.

8 Xu CS, Chang CF. Expression profiles of the genes associated with metabolism and transport of amino acids and their derivatives in rat liver regeneration. Amino Acids 2008; 34: 91-102.

9 Nunes PH, Calaza Kda C, Albuquerque LM, Fragel-Madeira L, ShollFranco A, Ventura AL. Signal transduction pathways associated with ATP-induced proliferation of cell progenitors in the intact embryonic retina. Int J Dev Neurosci 2007; 25: 499-508.

10 Edwards DR, Mahadevan LC. Protein synthesis inhibitors differentially superinduce $c$-fos and $c$-jun by three distinct mechanisms: lack of evidence for labile repressors. Embo J 1992; 11: 2415-24.

11 Clark DE, Errington TM, Smith JA, Frierson HF Jr, Weber MJ, Lannigan 
DA. The serine/threonine protein kinase, p90 ribosomal S6 kinase, is an important regulator of prostate cancer cell proliferation. Cancer Res 2005; 65: 3108-16.

12 Zinck R, Cahill MA, Kracht M, Sachsenmaier C, Hipskind RA, Nordheim A. Protein synthesis inhibitors reveal differential regulation of mitogen-activated protein kinase and stress-activated protein kinase pathways that converge on Elk-1. Mol Cell Biol 1995; 15: 4930-8.

13 Cano E, Hazzalin CA, Mahadevan LC. Anisomycin-activated protein kinases p45 and p55 but not mitogen-activated protein kinases ERK1 and -2 are implicated in the induction of $c-f o s$ and $c-j u n$. Mol Cell Biol 1994; 14: 7352-62.

14 White-Gilbertson S, Kurtz DT, Voelkel-Johnson C. The role of protein synthesis in cell cycling and cancer. Mol Oncol 2009; 3: 402-8.

15 Kaczmarek L, Surmacz E, Baserga R. Cycloheximide or puromycin can substitute for PDGF in inducing cellular DNA synthesis in quiescent ЗТ3 cells. Cell Biol Int Rep 1986; 10: 455-63.

16 Connolly E, Braunstein S, Formenti S, Schneider RJ. Hypoxia inhibits protein synthesis through a $4 \mathrm{E}-\mathrm{BP} 1$ and elongation factor 2 kinase pathway controlled by mTOR and uncoupled in breast cancer cells. Mol Cell Biol 2006; 26: 3955-65.

17 Arora S, Yang JM, Hait WN. Identification of the ubiquitin-proteasome pathway in the regulation of the stability of eukaryotic elongation factor-2 kinase. Cancer Res 2005; 65: 3806-10.

18 Bagaglio DM, Cheng EH, Gorelick FS, Mitsui K, Nairn AC, Hait WN. Phosphorylation of elongation factor 2 in normal and malignant rat glial cells. Cancer Res 1993; 53: 2260-4.

19 Parmer TG, Ward MD, Yurkow EJ, Vyas VH, Kearney TJ, Hait WN. Activity and regulation by growth factors of calmodulin-dependent protein kinase III (elongation factor 2-kinase) in human breast cancer.
Br J Cancer 1999; 79: 59-64.

20 Salhia B, Tran NL, Symons M, Winkles JA, Rutka JT, Berens ME. Molecular pathways triggering glioma cell invasion. Expert Rev Mol Diagn 2006; 6: 613-26.

21 Giese A, Bjerkvig R, Berens ME, Westphal M. Cost of migration: invasion of malignant gliomas and implications for treatment. J Clin Oncol 2003; 21: 1624-36.

22 Reginato MJ, Mills KR, Paulus JK, Lynch DK, Sgroi DC, Debnath J, et al. Integrins and EGFR coordinately regulate the pro-apoptotic protein Bim to prevent anoikis. Nat Cell Biol 2003; 5: 733-40.

$23 \mathrm{Wu} \mathrm{H}$, Yang JM, Jin S, Zhang H, Hait WN. Elongation factor-2 kinase regulates autophagy in human glioblastoma cells. Cancer Res 2006; 66: 3015-23.

24 Reddy KB, Nabha SM, Atanaskova N. Role of MAP kinase in tumor progression and invasion. Cancer Metastasis Rev 2003; 22: 395403.

25 Yoeli-Lerner M, Toker A. Akt/PKB signaling in cancer: a function in cell motility and invasion. Cell Cycle 2006; 5: 603-5.

26 Chen Y, Matsushita M, Nairn AC, Damuni Z, Cai D, Frerichs KU, et al. Mechanisms for increased levels of phosphorylation of elongation factor-2 during hibernation in ground squirrels. Biochemistry 2001; 40: $11565-70$.

27 Collins NL, Reginato MJ, Paulus JK, Sgroi DC, Labaer J, Brugge JS. $G_{1} / S$ cell cycle arrest provides anoikis resistance through Erkmediated Bim suppression. Mol Cell Biol 2005; 25: 5282-91.

28 Tan TT, Degenhardt K, Nelson DA, Beaudoin B, Nieves-Neira W, Bouillet $\mathrm{P}$, et al. Key roles of BIM-driven apoptosis in epithelial tumors and rational chemotherapy. Cancer Cell 2005; 7: 227-38. 